
\title{
25 Research Square \\ Origin and Route of Severe Dust Storms in West Asia (with Horizontal Visibility Less Than 1000 Meters)
}

zainab Mohammadi

Shahid Beheshti University

hassan lashkari ( $\sim$ h-lashkari@sbu.ac.ir)

Shahid Beheshti University https://orcid.org/0000-0002-6007-7275

\section{Research Article}

Keywords: Dust sources, Dust storm, Horizontal visibility, HYSPLIT, Southwest Iran, West of Asia.

Posted Date: November 22nd, 2021

DOI: https://doi.org/10.21203/rs.3.rs-803972/v1

License: (c) (1) This work is licensed under a Creative Commons Attribution 4.0 International License.

Read Full License 


\section{Abstract}

Storms are intensified atmospheric phenomena which are sometimes accompanied by heavy rainfall and sometimes by dust. Dust storms, especially storms with horizontal visibility of fewer than 1000 meters, have always been harmful and detrimental to human comfort and health. In recent decades, the worrisome phenomena of conflict, climate change, and droughts have increased the frequency of dust storms in West Asia. Identifying the source and route of dust storms is the first step in limiting the harm they inflict. To investigate this phenomenon, using the daily data of the Meteorological Organization of Iran, storms with horizontal visibility of less than 1000 meters in the southwestern region of Iran, as one of the destination areas of these storms, in a statistical period of 33 years (1987 to 2019) was extracted. First, the monthly, seasonal and annual distribution of dust storms in 13 synoptic stations in this area was investigated. Then, using the site https://www.ready.noaa.gov/HYSPLIT by backward method from the GDAS data system with a step of 0.5 degrees, the origin and path of the storms were identified. Finally, maps of each route were drawn in ArcGIS 10.6. The findings of this study revealed that the biggest number of dust storms occurred in the winter, in terms of temporal distribution (38\% of storms). With $23 \%$ of storms, spring is in second position. In terms of monthly distribution, the month of January has the most storms, followed by February and December. Storms decrease in intensity as they move from the south to the north, and from the west to the east of the region. The central region of Iraq ranks first in terms of storm origin, accounting for $25 \%$ of all storms. If dust storms originating in western Iraq are added to this number, about $35 \%$ of storms in west Asia originate in western and central Iraq. Regarding the pattern of large-scale atmospheric circulation prevailing in the middle layer of the atmosphere in this region, most of these dust storms in the west-east direction, after passing through the center and south of Iraq, enter Iran. The study also shows that storms in Syria囚 Jordan or northwestern Saudi Arabia, are very thick. These storms cover the middle layer of the troposphere and then affect high stations such as Shahrekord and Yasuj with an altitude of more than 2000 meters.

\section{Introduction}

Dust events are one of the common phenomena in arid and semi-arid regions. Dust storms have farreaching detrimental effects on society, including human health (Davoudi and Jalali,2008; Lashkari and Kaykhosravi,2010; Ghaffari and Mostafazadeh,2016). Dust is a mass of solid sedimentary particles with a diameter of less than 50 microns that are scattered in the form of suspended particles in the atmosphere and reduce the horizontal visibility between 1-2 km (Reed and Nugent,2018). Dust particles smaller than $0.1 \mathrm{~mm}$ in diameter remain suspended in the air for a long time and easily enter the lungs via the respiratory system (Karimi et al, 2013). The effects of the dust phenomenon continue for a very long time from the main source. In recent years, in areas with low average rainfall, the phenomenon of dust has caused many problems (Jin et al, 2014; Schweitzer et al, 2018). Although dust is not a new climate phenomenon and has a history in the great plains of the United States with many displaced families (Mark et al., 2007). In the land of Sistan Iran (Iranmanesh et al., 2005) with the occurrence of

winds of one hundred and twenty days every year and in the land of Transoxiana (Shao and Dong, 2006) 
is very old, but today new living conditions, dust in the physical scene of daily life and Human health (Goudie and Meddelton, 2001) has shown and has had a greater impact. Research suggests communication disturbances in southern Libya are associated with attenuation of shortwave transmission during dusty days (Saleh and Abuhdima, 2001) and the increase in electrical stress of air during the occurrence of sand and dust storms (Saleh and Abuhdima, 2001) is related to the high abundance of some metal particles in the form of airborne in the air of cities. The dusty belt of the world, which stretches from the coasts of West Africa to the coasts of East Asia (Natsagdorja et al, 2003), also covers Iran. Related to the subject of the present study, Masoudian (2004) considers "dust" as the sixth factor affecting Iran's climate and (Saliqeh et al, 2008) wind as the fifth most important provincial factor such as Sistan and Baluchestan. Researchers outside the world's dust belt, level Lake Eyre Australia (Hamish and Andrew, 2008) and Zinc Belt, Deserts of Mongolia (Weihong et al., 2001), India (Buchany and Fazeli, 2011), Northern Nigeria, South Chad and West Asia (Ginoux, et al., 2012), Saudi Arabia (Prijith et al., 2013) and Mesopotamia (Cao et al., 2015) are considered as dusty springs of the world. The latest studies in the field of dust in the region include (Attiya and Jones, 2020). They surveyed the climatology of Iraqi dust events from 1980 to 2015 , and found that summer dust was more active than other seasons in northern Iraq, whereas southern and central Iraq were exposed. The highest frequency of dust storms is in spring and summer. Cities near-desert areas (e.g. Nasiriyah, Basra and Baghdad) are the most abundant. (Xu et al, 2020) identified and quantitatively analyzed dust paths in the Hexi Corridor and the results showed that the share of dust paths in Xinjiang and Mongolia is lower due to higher vegetation, more rainfall, and more particle size. (AlKheder and AlKandari, 2020) examined the impact of dust on the operations of Kuwait International Airport for 2016 to 2017 and the results showed that the average arrival and departure times, on the days when the dust occurred, were 42 and 17.2 days less than the reference days. (Khsufi et al, 2020) studied the spatial and seasonal variations of sand dust and their relationship with climatic conditions and vegetation in semi-arid regions of central Iran and the results showed that the intensity of dust is positively related to surface winds in summer and It has meaning. In recent years, 29 provinces of Iran were affected by the dust phenomenon (Nourizade and Bahrami, 2015). One of the main problems in the study of pollution such as dust is to quantify the relationship between air quality and the source of pollution. The first step in designing an effective pollution control strategy is to identify the source of pollutants. This is accomplished using a variety of techniques, including remote sensing, synoptic maps, numerical methods, and so on. One way to find sources of pollution is to use the airflow path. In this case, the return paths from the receiver point can determine the location of the spring (Petzold et al, 2009). This method has been used extensively to show how pollution is spread and to determine the source (Rousseau, 2004). Reduced. Thus wind dynamics play an essential role in particle transport and dispersion (Salazar et al, 1994; Ansari and Jamshidi, 2018). The method of calculating this model is a combination of Eulerian views (the total particle concentration in each network is determined along the path) and Langrange (particle concentration for each network is done using particle diffusion and transport). Therefore, HYSPLIT Is called the dual model ((Draxler et al, 2009). Due to the fact that the change in the dynamic and synoptic structure of atmospheric systems leading to the rise of dust is beyond the technical ability of humans. As a result, dust storms occurrence cannot be prevented climatically. In such conditions, the best option is to stabilize and strengthen the soil of dust sources. The 
adhesion of soil or sand grains is overcome when the wind speed in the lower levels of the atmosphere surpasses a specific limit, and the particles are forced to move. These suspended particles are eventually transported away by atmospheric currents, resulting in dust storms. As a result, one of the most critical steps in planning soil stabilization against severe winds is to identify sources of dust or sand formation. 2

\section{Methods}

Due to the prevailing circulation patterns in this region of Asia, especially in the cold period of the year, most dust storms that occur in the eastern Mediterranean to western Iran, have a west-east extension. The southwestern region of Iran was selected as the destination of these storms. To select dust storm samples, the following steps were taken:

1. To select samples of dust storms, synoptic stations in southwestern Iran (Khuzestan, Kohkiluyeh, Boyer-Ahmad and Chaharmahal, and Bakhtiari provinces) were selected. In this area, the number of dust storms has significantly increased in recent years.

2. To select sample stations, dust data of all synoptic stations (27station) of the above three provinces were received from the Meteorological Organization of Iran. According to the purpose of the study, which was to investigate the temporal, spatial distribution, and origin of severe dust in the last three solar cycles (33-year statistical base), 13 stations were selected from the above stations. Table 1 shows the specifications of selected stations.

3. Dust data of above 13 synoptic stations were arranged in a statistical period of 33 years. Then data (number of reports of dust phenomenon (nhz), number of reports with dust phenomenon (ndu), number of reports with sandstorm (nbdu), wind speed and horizontal visibility and codes (06.07, $08.09,30.31,32.33,34.35,98)$ were extracted from the data of the Meteorological Organization. Table 1 shows an example of code related to dust storms.

4. After sorting the data, the dust storm with horizontal visibility of less than 1000 meters (codes 30 to 35) was separated from the other codes.

5. In the next step, the days with dust reported from each station were extracted daily, monthly, seasonally, and annually in Excel. Therefore, the columns shown on the graphs are the number of dust storms reported at each station in terms of the day, month, season or year.

6. In the next step, monthly and seasonal dust maps are drawn using ArcGis10.6 software. Thus, the topography of the area is shown as a zone, and the quantitative characteristics of dust events are displayed as a Bar / Column.

7. In the next step, the days with a horizontal view of fewer than 1000 meters were arranged for every 13 stations in an Excel file.

8. Thus, 627 days of dust with the visibility of fewer than 1000 meters from the selected stations were reported.

9. Then, applying the criterion that the dust phenomenon was reported in at least half of the stations, the final samples were selected. 
10. Using this criterion, 64 days in the 33-year statistical period had this feature. These storms were selected as a study sample.

11. In the next step, using the site https://www.ready.noaa.gov/HYSPLIT with the method (Backward) of the GDAS data system with a step of 0.5 degrees was drawn the origin of dust storms in southwestern Iran. These data have been available since 2007. Therefore, for all 64 days (study sample) it was not possible to draw the origin of storms using the hysplit index. Thus, only for 33 days (study sample), it was possible to draw the origin diagram.

12. After examining all the hysplits, it was found that dust storms originate from 7 main sources, which are generally located in three countries (Iraq, Saudi Arabia, and Syria).

13. The most frequent sources of dust production in these three countries include (east, centre, and west of Iraq, east and north of Syria, northwest of Saudi Arabia). To show the sources of dust production, topographic maps of these countries were prepared, and the boundaries of deserts are shown on them.

14. Finally, the source and route maps of storms are drawn once based on dust production areas (origin) and once based on dust receiving stations in ArcGis10.6 software environment.

The selected area for this study is West Asia. This region has some of the world's and the Middle East's most important population, economic, industrial, and agricultural regions, as well as oil and gas deposits. Any climatic hazard can have a negative impact on the activities listed above. The population of the area's health has also been put in jeopardy by these storms. More than 40 million people are affected by the detrimental effects of storms of various origins when the population of towns and villages in their route is taken into account. This research seeks to identify the origin and direction of these storms. By identifying sources of dust production, to help managers for soil consolidation and stabilization projects. Figure 1 and Table 2 show the geographical location of the study area and the distribution of selected stations for selecting storm samples.

\section{Results And Discussion}

Dust and sand storms are atmospheric phenomena resulting from the joint action of environmental and human factors. A human-degraded environment and prone to dust rising along with weather conditions are the sum of the factors that make up a dust storm or sandstorm. However, not a new phenomenon, dust storms, the improper and unprincipled human use of the environment has greatly exacerbated this phenomenon. Despite the fact that Syria, Iraq, and southwestern Iran are relatively rainy areas with rich surface water reserves in the Middle East and have relatively good vegetation. But, in recent years, the phenomenon of dust has intensified. Sometimes the intensity of dust storms is so great that people's normal lives are disrupted, and many social and economic activities are shut down. Besides, the health of the residents of this area is in danger. In this part of study, storms with a visibility of fewer than 1000 meters, which almost disrupts daily activities, are examined. As mentioned, the stations in southwestern Iran have been selected as the end route of storms that are generated from dust sources in Syria, Iraq, 
and Saudi Arabia. Therefore, first, the temporal and spatial distribution of these storms was investigated. These findings are presented in two parts as follows.

\subsection{Temporal distribution - location of dust storms with a visibility of less than 1000 meters}

\subsubsection{Seasonal distribution of storms}

Figure 2 and Table 3 show the seasonal distribution of dust storms over the entire statistical period at each station in the study area. In general, it can be said that the southwestern region of Iran is a polluted region in terms of the dust storm phenomenon. This phenomenon has been growing in recent years, especially in the cold months of the year. Iran has been one of the regions affected by dust storms, especially in recent years. In a 33-year study period, a total of 3027 cases of dust storms with visibility of fewer than 1000 meters from the southwestern region of Iran have been reported. Of these, 1153 cases (about 38.1\%) occurred in winter. Thus, the highest number of dust storms in this region occurs in winter. Spring is in second place with 711 cases (about 23.5\%) of recorded storms. Autumn is in third place with 627 cases (about 20.7\%) of dust storms. Summer has the lowest number of dust storms with 536 cases (about $17.7 \%$ ). In terms of synoptic patterns in the West Asian region, the largest number of unstable systems enter the region in late autumn and continue until early spring. But in the hot period of the year, with the dominance of the Arabian Sub Tropical anticyclone over the region, more stable conditions prevail in the West Asian region, and the number of dust storms decreases.

\subsection{Analysis of temporal changes of dust storms with horizontal visibility of fewer than 1000 meters in the southwest of Iran}

Figure 3. shows the temporal changes of dust storms in southwestern Iran. As can be seen, the distribution of storms with horizontal visibility of fewer than 1000 meters has had periodic fluctuations. These storms show a significant increase between 2008 and 2012. The years 2008 and 2009 had the worst conditions in terms of the number of dust storms in the statistical period of 33 years. In 2008, about 225 cases, in 2009, 243 cases of dust storms with horizontal visibility below 1000 meters were recorded. Between 2013 and 2017, there was a significant reduction in the number of dust storms. But again in 2018 , and especially in winter, the number of storms has increased significantly.

\subsection{Spatial distribution of the origin and frequency of dust storms}

Table 4 shows the spatial distribution of dust storms by each station. As can be seen, the number of days reported with dust storms greatly varies depending on the geographical location and altitude of the stations. The highest number of dust storms with horizontal visibility less than 1000 meters (since 2007), 33 cases from Abadan and Ahvaz stations, in the low altitude region of Khuzestan province and the lowest number with 5 cases from Koohrang station with a height of 2365 meters in Chaharmahal and Bakhtiari province was reported.

The dust storms observed from different locations had distinct causes, according to preliminary studies. The majority of these storms originated in seven separate places. Storms began in nine separate places 
and entered specific stations, according to preliminary findings. Center of Iraq

- Western Iraq

-South Iraq

-East Iraq

-Eastern Mediterranean countries

-The Arabian Peninsula

-Central and Northeast Africa

- far Distant resources in Eastern Europe

- and local resources within the study area

In practice, the number of dust storms of African and far Distant in Eastern Europe resources origin was very small. These two sources were excluded from the calculation table. Table 4 shows the main source of these storms at each station. In Abadan, Omidiyeh, Bostan, and Bandar Mahshahr stations, the source of the largest number of dust storms with visibility of fewer than 1000 meters from the centre of Iraq. At Dogonbadan station, Safi Ayad Dezful, Masjed Soleiman, the storms were mostly of local origin. For Shahrekord, Koohrang, and Yasuj stations, which are located in the higher western part of the study area, the source of dust storms was Syria and Jordan. $25.93 \%$ of dust storms with visions of less than 1,000 meters originated in central Iraq. About $20 \%$ of the storms in this area also originated from local sources. Dust sources in Syria and Jordan were the source of about 16 percent of the region's storms.

\section{Frequency and path of dust storms in each of the sources.}

In this part of research, the number of storms that have entered the study area from any origin has been investigated and analyzed.

\subsubsection{Source of the Eastern Mediterranean countries.}

This source includes Syria, Lebanon, and Jordan. The countries on the eastern shores of the Mediterranean, especially Syria and Jordan, are the source of a large number of severe dust storms in the southwestern region of Iran. Although these countries seem to be far from the study area. However, this study showed that a large number of severe storms in the region originate from these sources.

Geological, climatic and topographic characteristics and, most importantly, the phenomenon of war in the last decade in this part of Syria have been very effective to prepare the region for dust. Almost half of the storms originating in the eastern Mediterranean originate in northern Syria. However, the storms in this area have reached all the stations in this area. But the storms of the high stations east of the study area, 
such as Koohrang, Yasuj, Shahrekord, and Borujen stations, originated only from this area. In total, 47 dust storms started from this region and entered the stations of southwestern Iran.

\subsubsection{Dust resources of Iraq}

Four areas in Iraq are the source of dust storms entering southwestern Iran. These areas are as follows:

\subsubsection{Source of southern Iraq}

This source is located in the southern part of Iraq and includes (the provinces of Muthanna, Najaf, Karbala, and parts of Al-Anbar province) which is known as Al-Hajarah. Much of it is adjacent to the AlSham Desert and the Al-Nafood Desert in northern Saudi Arabia. A total of 29 storms in a study period originated from this region and entered southwestern Iran (Figure 5).

\subsubsection{Source of western Iraq}

This source of dust is located in western Iraq. Geographically, this region includes the provinces of AlAnbar and Ninawa. This area coincides with the desert areas of western Iraq and shares the "Bādiyah Ash-Shām" desert on the Syrian border. The region has also been severely affected by the devastating effects of the war against ISIS in recent years. In terms of climate, this part of Iraq has little rainfall. In terms of vegetation, it is very poor due to climatic conditions. In total, 31 cases of dust storms reported from stations in southwestern Iran (during the study period) originated in this region. As can be seen, the primary source of these storms is close to the border with Syria. The main destination of these storms was low altitude stations in Khuzestan province. Rarely has a storm from this source entered highaltitude stations in the east of the study area (Figure 6).

\subsubsection{Source of the center of Iraq}

This section belongs to Iraq's central region, which comprises the provinces of Kirkuk, Erbil, Mosul, and Samarra. This source is in western Iraq, near the source. It was sometimes impossible to tell which of these two sources was causing the storms. This source is also linked to the western Iraqi deserts. As a result, this part of Iraq is also prone to dust rising due to its topographic and geological conditions. In total, 76 cases of dust storms recorded at stations in southwestern Iran originated in this region. Almost all of these dust storms have entered the Low height stations of Khuzestan province. As can be seen, none of the dust storms in central Iraq have hit the high stations in southwestern Iran (Figure 7).

\subsubsection{The source of the eastern region of Iraq}

This region is from Iraq in the neighborhood of Khuzestan and llam provinces in Iran. In other words, this region of Iraq is the closest source of dust production to the study area. The region includes the provinces of Diyala, Wasit, and Maysan in eastern Iraq, all of which have been at war for eight years. As a result, the lands of these provinces have been severely damaged by the war and are prone to dust production. Most of the dust storms originating from this region have entered Khuzestan province from Iraq, especially the 
north and west of this province. Interestingly, the dust storms generated from the Source of this region have rarely entered the south of Khuzestan province and the high stations east of the study area (Figure8).

\subsubsection{Dust Source in Saudi Arabia}

In total, 21 dust storms have entered southwestern Iran from this region. Dust storms that entered southwestern Iran from Saudi Arabia originated in two parts of the country. Fewer dust storms have started in the southern deserts of the country. But most of the storms started in the northwestern deserts, adjacent to the southern deserts of Iraq. These deserts are known as the deserts of Badieh al-Sham and the deserts of Nafud. (Figure 9).

\subsubsection{Internal sources of dust production}

Generally, 59 of the dust storms reported from area stations originated from the inland sources. The soil and vegetation resources of this region from Iran have undergone drastic changes, especially in the last four decades. Part of these changes in land use is related to changes in the hydrology of catchments in this area. Water transfer and construction of dams on the tributaries of the two catchments of Karun and Karkheh rivers and the reduction of water in these rivers have made the vegetation of the lands of these two basins very vulnerable. The second phenomenon has strongly affected the destructive effects of 8 years of war, soil and vegetation of Khuzestan plain and has made the conditions more prone to dust rise. As can be seen, the origin of most of these storms is from the southern and western parts of Khuzestan province. This region is located in the neighborhood of Iraq and has been affected more than other parts of the province by the destructive effects of the war. Some of these dust storms have affected even the highest stations in the eastern part of the region. (Figure 10)

\subsection{Origin, destination and route of dust storms based on station centers.}

This part of the research investigates the origin, destination, and route of dust storms based on station centers. The origin and direction of dust storms at the stations based on latitude were as follows.

Mahshahr Port Station - This station is located in the southernmost part of the study area and on the north coast of the Persian Gulf. Most of the dust storms entering the station come from central Iraq (35\%). About $17 \%$ of the dust storms entering the station are of local origin. A number of storms have also entered the station from the west and east of Iraq.

Abadan Station - At this station, $42 \%$ of dust storms originate from central Iraq. Storms originating in western Iraq are in second place with $24 \%$. Storms of Saudi and Syrian origin are in third place with $12 \%$ of storms.

Omidieh Station - This station is located a little further north than the previous two stations. In terms of topography, it is higher than the previous two stations. As can be seen, the highest number of dust storms 
entering the station (42\%) originate in the central region of Iraq. About $23 \%$ of the station's dust storms are of local origin. Storms originating in southern Iraq rank third with 19 percent.

Dogonbadan Station - This station is located in the southeast of the study area. An interesting phenomenon in this station is the prevalence of storms of local origin. In total, 19 dust storms with a visibility of less than 1000 meters were reported in this station. Of these, $37 \%$ were of local origin. This means that the source of this storm was inside Khuzestan province. Storms originating in southern Iraq are in the second place with $26 \%$.

Ahvaz Station - This station is located in the metropolis of Ahvaz. 33\% of the storms entering the station originated from central Iraq. $24 \%$ of the storms originated locally or from a source in the southeast of Ahwaz city. Dust storms originating in western Iraq and Syria each account for 15 percent of incoming storms.

Ramhormoz Station - This station is located in the north of Ahvaz city and the middle of Khuzestan province. 39 percent of the storms entering the station came from dust sources in eastern Iraq, 28 percent from central Iraq, and 22 percent from western Iraq.

Bostan Station - This station is located in the westernmost part of Khuzestan province and borders with Iraq. Most of the dust storms came from central Iraq and Syria, and Jordan. In total, more than $70 \%$ of the dust storms in this area have entered the station from the sources of the above three dust sources.

Safiabad Dezful Station - This station is the northernmost station of Khuzestan province and is located at the end of the low plain of Khuzestan. After this city, the mountains of Central Zagros begin. About $40 \%$ of the incoming dust storms with this station were of local origin. In other words, the largest number of dust storms entering this station were generated in and around this station. The two springs in eastern and central Iraq are next with a total of $32 \%$ of storms.

Masjed Soleyman Station - About 31 dust storms were reported from this station. Therefore, this station is also one of the areas prone to dust storms in this region of the country. In this station, the highest number of dust storms are of local origin. Thirty-two percent of storms are generated within the province. Eastern Iraq ranks second with about 22 percent of storms, and central Iraq ranks third with 12 percent of storms.

Stations of the high part of the study area - In the eastern part of the study area, there are three stations: Yasuj, Shahrekord, and Koohrang. The height of these stations is 1816.3, 2048.9, and 2365 meters, respectively. During the statistical period, 23 storms were reported from these three stations, which has decreased significantly compared to the stations in the low region of Khuzestan province. The highest number of storms entering these stations from Syria and Jordan (Eastern Mediterranean countries) was $60 \%$ for Koohrang station, $50 \%$ for Shahrekord, and $37.5 \%$ for Yasuj, respectively.

\section{Conclusion}


However, the storms are an inherent phenomenon of any climate. The dust storms are considered a climatic hazard because of the devastating effects on health and living organisms and the constraints it imposes on daily human activities. This issue has become a social crisis in arid and semi-arid regions, which are also facing the problem of water shortage. Given that the occurrence of strong winds lies in the nature of these climates, and we cannot prevent their creation, it is necessary to control and strengthen the soil in these areas, to prevent soil particles from rising in these areas. To achieve this goal, one must first identify the origin or sources of dust particles. By adopting appropriate methods, it made the soil resistant to winds of different intensities. The second issue is identifying the path of these storms. As mentioned, the first storms with a visibility of less than 1000 meters, which are severe dust storms, were identified and extracted.

Then, using the site https://www.ready.noaa.gov/HYSPLIT, the origin and path of the storms were identified by the method (Backward) of the GDAS data system with a step of 0.5 degrees.

The results of this study showed that:

1-In a 33-year statistical period, a total of 3027 storms were reported from selected stations. Of these, 1153 cases (about $38 \%$ ) occurred in winter. Spring is in second place with 711 cases ( $25.5 \%$ of storms). Thus, the highest storms occur when unstable systems dominate the area. Due to the climatic conditions in the southern part of Iraq and southwestern Iran, these seasons are associated with the period of agricultural activities. The entry of large dust particles can cause serious damage to agricultural products in the region.

2- In terms of the monthly distribution of storms, the highest number of dust storms occurred in January (501 days), February (344 days), and December (319 days), respectively. These months coincide with the cultivation of crops such as vegetables, tomatoes, cucumbers, and other saffron crops in southwestern Iran and southern Iraq. Dust particles from dust storms have a direct impact on the health of these products.

3. During the statistical period, the highest number of storms occurred from 2008 to 2012.

4. In total, the number of storms decreases from south to north and from west to east of the study area. The number of storms has dramatically decreased with rising altitude in terms of altitude distribution. This shows that the majority of the storms have arrived from beyond the area. Furthermore, the majority of storms occur in the lower layers of the atmosphere.5. As we have seen, the source in central Iraq, with $25 \%$ of the storms created, have the highest share among other dust sources. With the addition of sources in western Iraq, which are very close to these sources, $35 \%$ of dust storms in the region originate in western and central Iraq. This area corresponds to the provinces of Al-Anbar, Ninawa, and Sala ad -Din in Iraq. The western deserts of Iraq are located in these provinces.

6- Local Source, especially Source which are located in the southern parts of Khuzestan province of Iran and around the city of Ahvaz, are in the second place in terms of the origin of storms entering the region. 
Changes that have been made in recent years in the hydrology and physiography of catchments in this area. The changes which were made in recent years, in terms of hydrology and physiography of the catchments of this region, have caused significant changes in land use and the destruction of vegetation in the region. The construction of several dams on the important rivers of this region (Karkheh, Dez, and Karun rivers) as well as the transfer of water from the catchments of these rivers to other catchments has caused a severe reduction in the discharge of these rivers. As a result, with the loss of vegetation, which was generally irrigated by the seasonal floods of these rivers, new dust sources have appeared within the area. Due to the soil texture of the area, which are generally made of clay and sand, they can easily rise from the ground with low-velocity currents.

7- As a result, the main source of dust storms in the southern and central stations of Khuzestan province is from the source of central and western Iraq. For the more northern stations of the province, dust storms are the source in the east of Iraq. But to the east of the study area, or higher stations, the source of dust storms is transferred to more distant countries such as Syria, Jordan, and northwestern Saudi Arabia. Therefore, dust sources in nearby lands and local source are not able to transfer dust to farther and higher stations. Therefore, the synoptic pattern of storms in the lower regions of Khuzestan province is different from the synoptic pattern that leads to the transfer of soil particles from distant source in Syria and Jordan to the highlands of Iran. The discrepancies in the synoptic pattern of dust storms in Khuzestan's lowlands and highlands need to be researched further, and these structural distinctions in the synoptic and dynamics of systems will be presented in another article. Thus, controlling and reducing the destructive effects of dust storms on the life and activities of urban and rural communities, as well as the environment of the region, firstly, depends on the collective effort between the four countries of Iran, Iraq, Syria and Saudi Arabia. Despite the fact that these storms' final destination is within the low-lying region of southwestern Iran, fine dust collects in this area due to topographic characteristics. However, the majority of these storms sweep across Iraq and its major cities, finally reaching southwestern Iran. As a result, all of these dust storms harm all of the country's residential areas as they pass through. Therefore, controlling the dust phenomenon requires careful study of the nature, type and grain size of the soil of dust production springs and then adopting appropriate methods for soil stabilization, appropriate to the soil type of each sources. Regarding the future outlook (reduced water inflows of the Tigris and Euphrates rivers) in Iraq and the resulting desertification, the destructive effects of war on the region's vegetation and soil, and the weakness of management, this phenomenon in the not-too-distant future It will become an environmental and social crisis. The results of this research with studies (Alijani and Koohzad, 2011; Azizi et al., 2012; Lashkari and Sabouei, 2013; Jahanbakhsh et al., 2014; Naserpour et al., 2015; Naserzadeh And Fathi, 2016 and Kikhosravi and Hasili, 2017,Khodam et al,2020) are consistent.

Recent studies such as( Cao et al., 2015, in their research, determined the identification of dust storm source areas in West Asia using multiple environmental datasets and introduced areas in Syria, Iraq, Jordan, Iran, and Saudi Arabia as the source of dust. Our results are consistent with this result. Suresh et al., 2021 in their research on Seasonal variability in aeolian dust deposition fluxes and their mineralogical composition over the Northeastern Arabian Sea and the results showed that major dust sources to the Northeastern Arabian Sea are from northeast Africa, Arabian Peninsula, and southwest Asia. 


\section{Declarations}

\section{Acknowledgments}

This research is the result of the postdoctoral project No. 98026868 and is supported by the Iran National Science Foundation INSF.

\section{References}

1. Alijanei, B., \& Raeispoor, K. (2011). Statistical, Synoptical Analysis of Sand Storms in SE IRAN.(Study Case: Region of SISTAN). Arid Regions Geographic Studies. 2011; 2 (5) :107-130.

2. AlKheder, S., \& AlKandari, A. (2020). The impact of dust on Kuwait International Airport operations: a case study. International Journal of Environmental Science \& Technology (IJEST), 17(7).

3. Ansari, A., \& Jamshidi, R. (2018). Identification of sources and tracking dust storm routes from domestic sources entering Arak metropolitan area using HYSPLIT model. Environmental Sciences. 16 (1), 101-110.

4. Attiya, A. A., \& Jones, B. G. (2020). Climatology of Iraqi dust events during 1980-2015. SN Applied Sciences, 2(5), 1-16.

5. Azizi, Gh., Shamsipour, A., Miri, M. and Safarrad, T., (2012), Synoptic and remote sensing analysis of dust events in southwestern Iran", Journal of Natural Hazards, No.64, pp.1625-1638.

6. Buchany, M., Fazeli, D. (2011). Environmental challenges and its consequences, dust and its consequences in the West of Iran. Journal of Policy making, (3), 125-146.

7. Cao, H., Amiraslani, F., Liu, J., Zhou, N. (2015). Identification of dust storm source areas in West Asia using multiple environmental datasets. Science of the Total Environment, 502, 224-235.

8. Draxler, R., Stunder, B., Rolph, G., Stein, A., Taylor, A. (2009). Hybrid single-particle Lagrangian integrated trajectories 4 user's guide. NOAA Tech. Memo, ERL-ARL.

9. Ghaffari, D., \& Mostafazadeh, R. (2015). An investigation on sources, consequences and solutions of dust storm phenomenon in Iran. Journal of Conservation and Utilization of Natural Resources, 4, 107-125.

10. Ginoux, P., Prospero, J. M., Gill, T. E., Hsu, N. C., Zhao, M. (2012). Global-scale attribution of anthropogenic and natural dust sources and their emission rates based on MODIS Deep Blue aerosol products. Reviews of Geophysics, 50(3).

11. Goudie, A. S., Middleton, N. J. (2001). Saharan dust storms: nature and consequences. Earth-science reviews, 56(1-4), 179-20

12. Iranmanesh, F., M. Arabkhedri and M. Akram. 2005. Investigation on dust storm sources and their spreding properties in Sistan storm using image processing. Pajoohesh and Sazandegi, 67: 25-33 .

13. Jahanbakhsh, S., Zeinali, B., \& Asghari, S. (2014). Analysis and Clustering of Dust Storm Frequency in Iran by Fuzzy Clustering (FCM). Journal of Urban Ecology Researches, 5(10), 85-98. 
14. Jalali, N., \& Davoudi, M. H. (2008). Inspecting the originsand causes of the dust storms in the Southwest andWest parts of Iran and the regions affected. Internal reports of Soil Conservation and Watershed anagement Research Institute (SCWMRI), Iran.

15. Jin, Q., Wei, J., \& Yang, Z. L. (2014). Positive response of Indian summer rainfall to Middle East dust. Geophysical Research Letters, 41(11), 4068-4074.

16. Karimi, M, Yazdani, M. H, Naderi, A (2013): The effect of 120-day winds on the safety of Sistan region. Geography and Environmental Planning, 24(2), pp: 25-27.

17. Kaykhosravi, Q. and Hasili, M. (2017). Trajectory simulation of some examples of severe dust storms in Kermanshah province from the perspective of synoptic and HYSPILT model, Quarterly Journal of Natural Geography, 10 (37), 59-82. magiran.com/p1794099.

18. Khusfi, Z. E.; M. Khosroshahi, F. Roustaei and M. Mirakbari. (2020). Spatial and seasonal variations of sand-dust events and their relation to atmospheric conditions and vegetation cover in semi-arid regions of central Iran. Geoderma, 365: 114-225.

19. Lashkari, H., Kaykhosravi, Q. (2010). Statistical Analysis of Thunderstorms and Blown Dust during the Statistical Period of 2004-1990 in Hamadan Province (1). Scientific- Research Quarterly of Geographical Data (SEPEHR), 19(75), 60-66.

20. Lashkari, H., Sabuei, M. (2013). Synoptic analysis of dominant patterns in Khuzestan province's dust storm. Scientific- Research Quarterly of Geographical Data (SEPEHR), 22(87), 32-38.

21. Lashkari, H.; Z. Mohammadi and M. Jafari. (2020). Investigation on dynamical structure and moisture sources of heavy precipitation in south and south-west of Iran. Arabian Journal of Geosciences, 13: 1-15.

22. Mark, B. W. B. J. Skinner, S. G. Porter, (1997). Dangerous Earth; Canada; JohnWiley \& Sons Press.

23. Masoodian, S. (2014). Sistan \& Balouchestan 120 Days Wind. Journal of Applied Climatology, 1(1), 37-46.

24. McGowan, H and A. Clark. (2008). Identification of dust transport pathways from Lake Eyre, Australia using Hysplit. Atmospheric Environment, 42: 6915-6925.

25. McGowan, H., \& Clark, A. (2008). Identification of dust transport pathways from Lake Eyre, Australia using Hysplit. Atmospheric Environment, 42(29), 6915-6925.

26. Naserpour, S., Alijani, B., Zeaiean, P. (2015). Sources of Dust Storms in South West Iran Using Satellite Images and Weather Maps. Physical Geography Research Quarterly, 47(1), 21-36. doi: 10.22059/jphgr.2015.53676

27. Naserzadeh, M., fatahi, H. (2016). The Recognition of Synoptic and Local Scale Factors Influencing the Occurrence of the Dust Phenomenon in llam. Regional Planning, 6(21), 57-74.

28. Natsagdorja, L. D. Jugdera, Y. S. Chungb, (2003). Analysis of Dust Storms Observed in Mongolia during 1937-1999. Atmospheric Environment, 37:1401-1411.

29. Nourizadeh.H, Bahrami.H (2015): Investigation of the relationship between aerosol concentration with surface moisture and soil particle size distribution and the use of removable wind erosion 
simulator in west desert areas in Khuzestan province, Journal of Geographical Exploration of Desert Areas, 5(1), pp: 167-183.

30. Petzold, A., Rasp, K., Weinzierl, B., Esselborn, M., Hamburger, T. and Dornbrack, A., 2009. Saharan dust absorption and refractive index from aircraft-based observation during SAMUM2006. Tellus. 61, $118-130$.

31. Prijith, S. S. K. Rajeev, B. V. Thampi, S. K. Nair, M. Mohan, (2013). Multi-year observations of the spatial and vertical distribution of aerosols and the genesis of abnormal variations in aerosol loading over the Arabian Sea during Asian Summer Monsoon Season. J. Atmos. Solar-Terr. Phys. 105: 142-151.

32. Reed, L., \& Nugent, K. (2018). The health effects of dust storms in the Southwest United States. The Southwest Respiratory and Critical Care Chronicles, 6(22), 42-46.

33. Rousseau, D.D., Duzer, D., Etienne, J.L., Cambon, G., Jolly, D., Ferrier, J. and Schevin, P., 2004. Pollen record of rapidly changing air trajectories to the North Pole. Journal of Geophysical Research, 109.

34. Salazar, C., Alvarez, C., Silva, H.A. and Dorantes, C.,1994. Radioactivity in air around nuclear facilities in Mexico. Environmental International. 20, 747-756.

35. Saleh, I. M. E. M. Abuhdima, (2011). Effect of Sand and Dust Storms on Microwave Propagation Signals in Southern Libya.Journal of Energy and Power Engineering. 5: 1199-1204.

36. saligeh, M., bareimanei, F., esmaeilnegad, M. (2008). Climatical Regionalization on Sistan \& Balouchestan Province. Geography And Development Iranian Journal, 6(12), 101-106. doi: $10.22111 /$ gdij.2008.1245

37. Schweitzer, M. D., Calzadilla, A. S., Salamo, O., Sharifi, A., Kumar, N., Holt, G., ... \& Mirsaeidi, M. (2018). Lung health in era of climate change and dust storms. Environmental research, 163, 36-42.

38. Shao, Y. Dong, C. H. (2006). A Review on East Asian Dust Storm Climate, Modelling and Monitoring. Global and PlanetaryChange; 52: 1-22.

39. Suresh, K., Kumar, A., Ramaswamy, V., \& Prakash Babu, C. (2021). Seasonal variability in aeolian dust deposition fluxes and their mineralogical composition over the Northeastern Arabian Sea. International Journal of Environmental Science and Technology, 1-14.

40. Weihong, Q. Lingshen, Q. Shaoyin, S. (2001). Variations of the Dust Storm in China and its Climatic Control, Journal ofClimate. 15: 1216-1229.

41. Xu, C.; Q. Guan, J. Lin, H. Luo, L. Yang, and Q. Wang.(2020). Identification and quantitative analysis of dust trajectories in the Hexi Corridor. Agricultural and Forest Meteorology, 291: 107-987.

\section{Tables}

Table 1. World Meteorological Organisation (WMO) recognised 11 weather codes relating to wind erosion. 
Weather description

Dust haze

Raised dust or sand 07

Well-developed dust whirls (dust devils) 08

Distant or past dust storm (distant at time of obs or past station in the past hour 09

DECREASED slight or moderate sand or dust storm with visibility $<1000 \mathrm{~m}$ but $>200 \mathrm{~m}$ 30

STABLE slight or moderate sand or dust storm with visibility $<1000 \mathrm{~m}$ but $>200 \mathrm{~m}$ 31

BEGUN or INCREASING slight or moderate sand or dust storm with visibility $<1000 \mathrm{~m}$ but $>200 \mathrm{~m}$

DECREASED severe dust storm with visibility $<200 \mathrm{~m}$

Stable severe dust storm with visibility $<200 \mathrm{~m}$

BEGUN or INCREASING severe dust storm with visibility $<200 \mathrm{~m}$

Thunderstorm with dust or sand storm

(O'Loingsighet al., 2014)

Table 2. Position of selected stations of the South West 


\begin{tabular}{llll} 
Station & Latitude & Longitude & Elevation \\
\hline Abadan & 30.37722 & 48.21472 & 6.6 \\
\hline Ahvaz & 31.34472 & 48.74417 & 22.5 \\
\hline Bandar-e- Mahshahr & 30.54556 & 49.15917 & 6.2 \\
\hline Borujen & 31.97889 & 51.29889 & 2260 \\
\hline Bostan & 31.70778 & 48.01 & 7.8 \\
\hline Dogonbadan & 30.34611 & 50.81917 & 726 \\
\hline Kuhrang & 32.45694 & 50.125 & 2365 \\
\hline Masjedsoleyman & 31.98333 & 49.24083 & 320.5 \\
\hline Omidiyeh (Aghajari) & 30.7425 & 49.68778 & 27 \\
\hline Ramhormoz & 31.27278 & 49.59639 & 150.5 \\
\hline Safiabad (Dezful) & 32.25333 & 48.43306 & 82.9 \\
\hline Shahrekord & 32.29222 & 50.83944 & 2048.9 \\
\hline Yasuj & 30.69861 & 51.555 & 1816.3
\end{tabular}

Table 3. Seasonal distribution of dust storms with horizontal visibility less than $1000 \mathrm{~m}$ southwest. 


\begin{tabular}{llllll} 
station & Spring & Winter & Autumn & Summer & Annual \\
\hline Abadan & 143 & 107 & 59 & 89 & 398 \\
\hline Ahvaz & 108 & 130 & 77 & 81 & 396 \\
\hline Bandar-e-Mahshahr & 75 & 72 & 59 & 66 & 272 \\
\hline Borujen & 2 & 34 & 20 & 2 & 58 \\
\hline Bostan & 95 & 135 & 57 & 60 & 347 \\
\hline Dogonbadan & 13 & 68 & 46 & 17 & 144 \\
\hline Kuhrang & 16 & 149 & 60 & 0 & 225 \\
\hline Masjedsoleyman & 104 & 117 & 46 & 96 & 363 \\
\hline Omidiyeh (Aghajari) & 51 & 53 & 30 & 42 & 176 \\
\hline Ramhormoz & 19 & 56 & 40 & 23 & 138 \\
\hline Safiabad (Dezful) & 69 & 95 & 47 & 46 & 257 \\
\hline Shahrekord & 6 & 68 & 52 & 4 & 130 \\
\hline Yasuj & 10 & 69 & 34 & 10 & 123 \\
\hline Sum & 711 & 1153 & 627 & 536 & 3027
\end{tabular}

Table 4.Spatial distribution of the origin of dust storms separately for each station 
station

Eastern Southern Iraq Iraq and Jordan

\begin{tabular}{|c|c|c|c|c|c|c|c|c|}
\hline \multirow[t]{2}{*}{ Abadan } & 0 & 2 & 4 & 14 & 4 & 8 & 1 & 33 \\
\hline & 0 & 6.06 & 12.12 & 42.42 & 12.12 & 24.24 & 3.03 & 100 \\
\hline \multirow{2}{*}{$\begin{array}{l}\text { Omidiyeh } \\
\text { (Aghajari) }\end{array}$} & 0 & 6 & 1 & 13 & 3 & 1 & 7 & 31 \\
\hline & 0 & 19.35 & 3.22 & 41.93 & 9.67 & 3.22 & 22.58 & 100 \\
\hline \multirow[t]{2}{*}{ Ahvaz } & 0 & 3 & 5 & 11 & 1 & 5 & 8 & 33 \\
\hline & 0 & 9.09 & 15.15 & 33.33 & 3.03 & 15.15 & 24.24 & 100 \\
\hline \multirow[t]{2}{*}{ Borujen } & 2 & 1 & 5 & 0 & 4 & 1 & 1 & 14 \\
\hline & 14.28 & 7.14 & 35.71 & 0 & 28.57 & 7.14 & 7.14 & 100 \\
\hline \multirow[t]{2}{*}{ Bostan } & 0 & 2 & 11 & 11 & 1 & 3 & 3 & 31 \\
\hline & 0 & 6.45 & 35.48 & 35.48 & 3.22 & 9.67 & 9.67 & 100 \\
\hline \multirow{2}{*}{$\begin{array}{l}\text { Bandar-e- } \\
\text { Mahshahr }\end{array}$} & 4 & 2 & 3 & 11 & 1 & 4 & 5 & 30 \\
\hline & 13.33 & 6.66 & 10 & 36.66 & 3.33 & 13.33 & 16.66 & 100 \\
\hline \multirow[t]{2}{*}{ Dogonbadan } & 3 & 5 & 2 & 0 & 1 & 1 & 7 & 19 \\
\hline & 15.78 & 26.31 & 10.52 & 0 & 5.26 & 5.263 & 36.84 & 100 \\
\hline \multirow[t]{2}{*}{ Ramhormoz } & 7 & 0 & 1 & 5 & 0 & 4 & 1 & 18 \\
\hline & 38.88 & 0 & 5.55 & 27.77 & 0 & 22.22 & 5.55 & 100 \\
\hline \multirow[t]{2}{*}{ Shahrekord } & 1 & 1 & 5 & 0 & 1 & 0 & 2 & 10 \\
\hline & 10 & 10 & 50 & 0 & 10 & 0 & 20 & 100 \\
\hline \multirow{2}{*}{$\begin{array}{l}\text { Safiabad } \\
\text { (Dezful) }\end{array}$} & 5 & 1 & 4 & 5 & 1 & 2 & 12 & 30 \\
\hline & 16.66 & 3.33 & 13.33 & 16.66 & 3.33 & 6.66 & 40 & 100 \\
\hline \multirow[t]{2}{*}{ Kuhrang } & 1 & 1 & 3 & 0 & 0 & 0 & 0 & 5 \\
\hline & 20 & 20 & 60 & 0 & 0 & 0 & 0 & 100 \\
\hline \multirow[t]{2}{*}{ Masjedsoleyman } & 7 & 4 & 2 & 5 & 2 & 1 & 10 & 31 \\
\hline & 22.58 & 12.9 & 6.45 & 16.12 & 6.45 & 3.22 & 32.25 & 100 \\
\hline \multirow[t]{2}{*}{ Yasuj } & 0 & 1 & 3 & 1 & 2 & 1 & 1 & 8 \\
\hline & 0 & 12.5 & 12.5 & 12.5 & 25 & 12.5 & 25 & 100 \\
\hline Sum & 30 & 29 & 47 & 76 & 21 & 31 & 59 & 293 \\
\hline
\end{tabular}




\section{Figures}

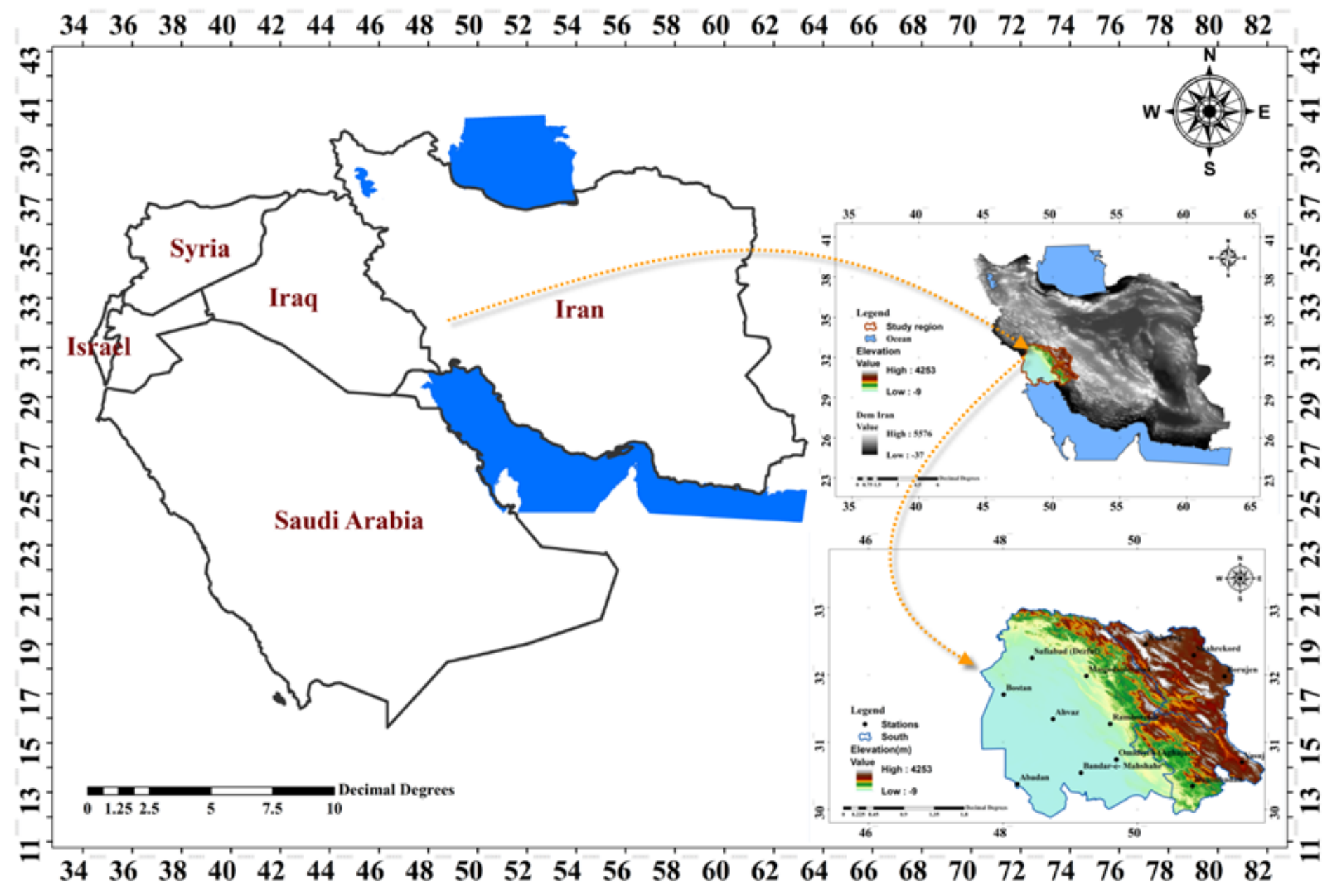

Figure 1

Location of stations and study area in the south and southwest of Iran 


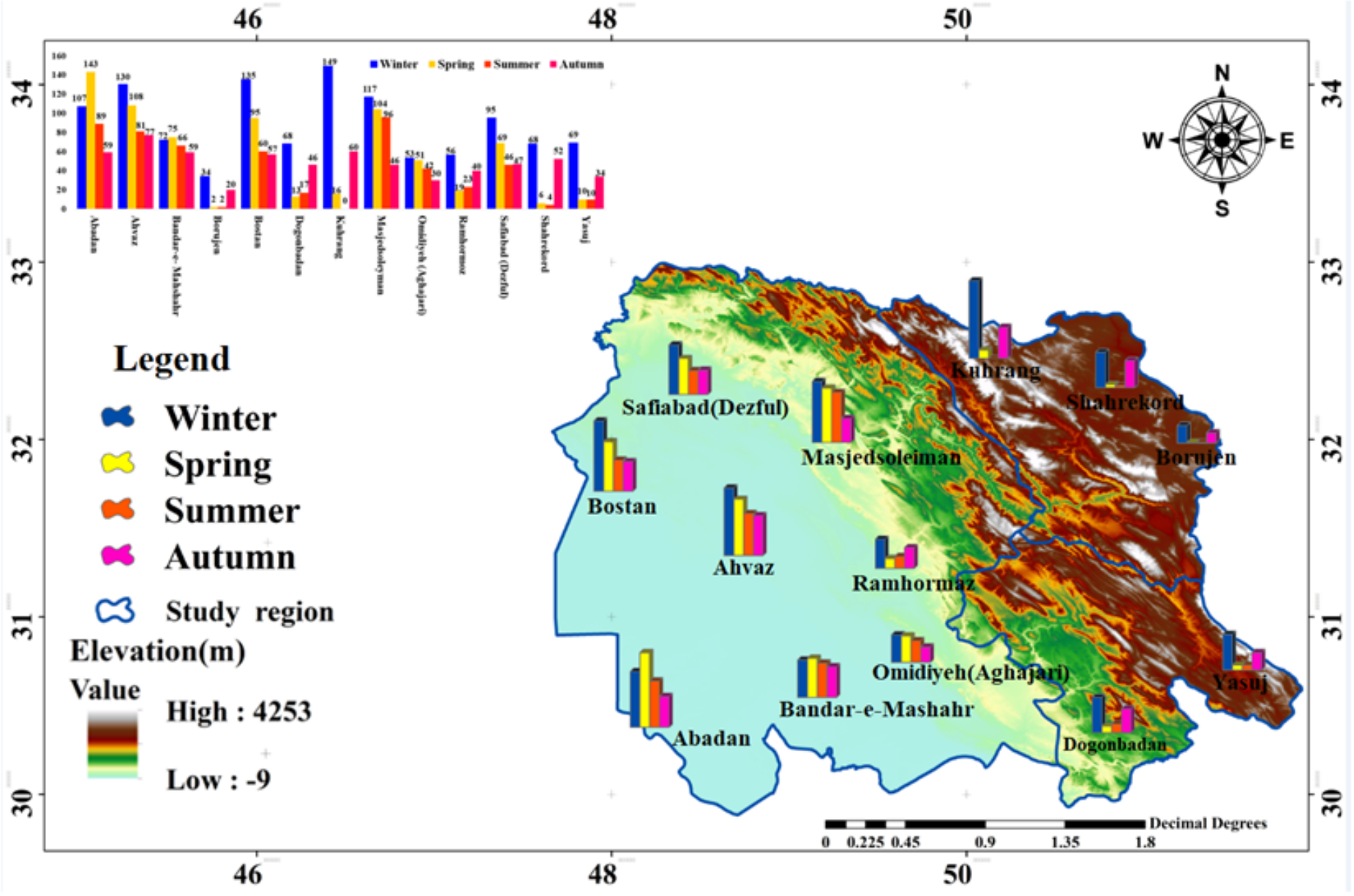

Figure 2

Seasonal distribution of dust storms with horizontal visibility less than $1000 \mathrm{~m}$ southwest.

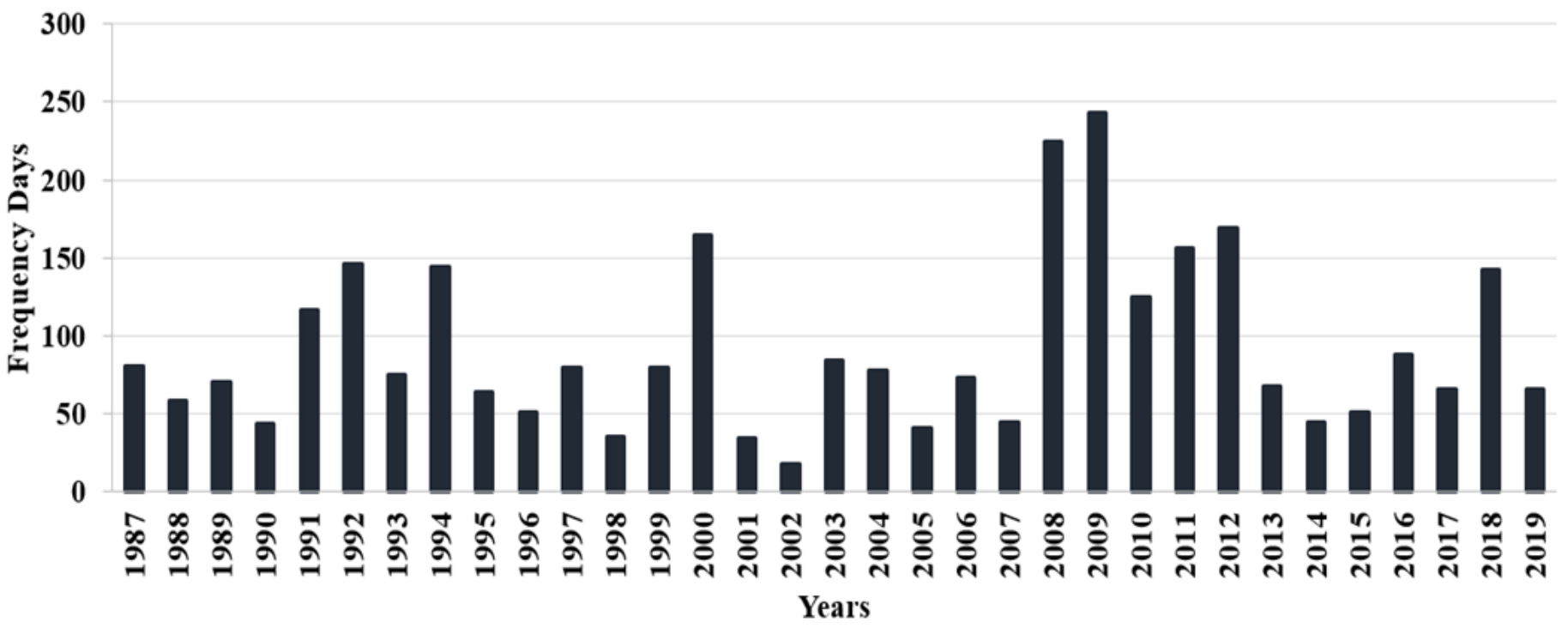

Figure 3

Temporal changes of dust storms with horizontal visibility of less than 1000 meters in the southwest 


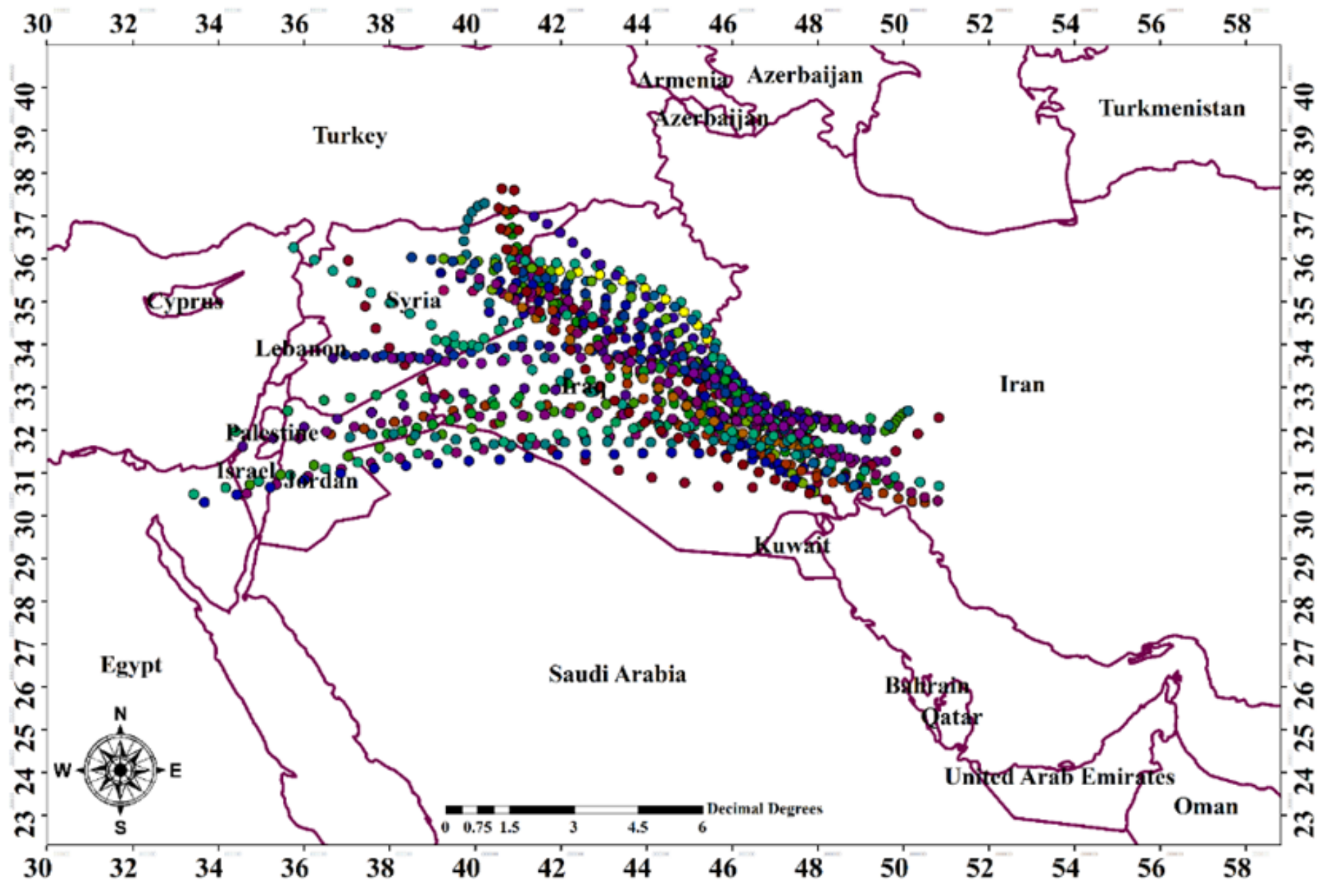

Figure 4

Origin, destination and direction of dust storms of Syrian and Jordanian origin 


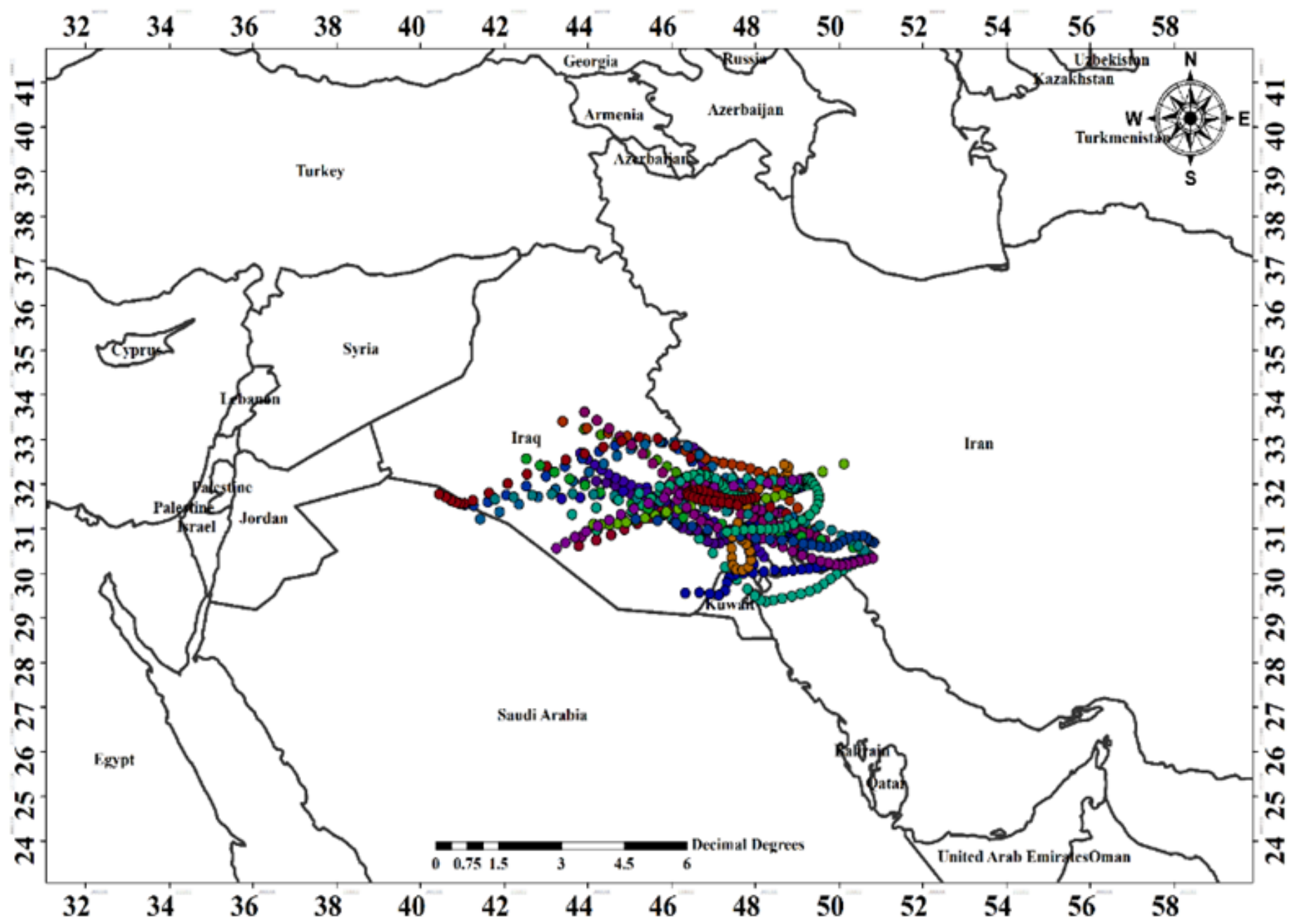

Figure 5

Origin, destination and route of movement of the dust source storm in southern Iraq 


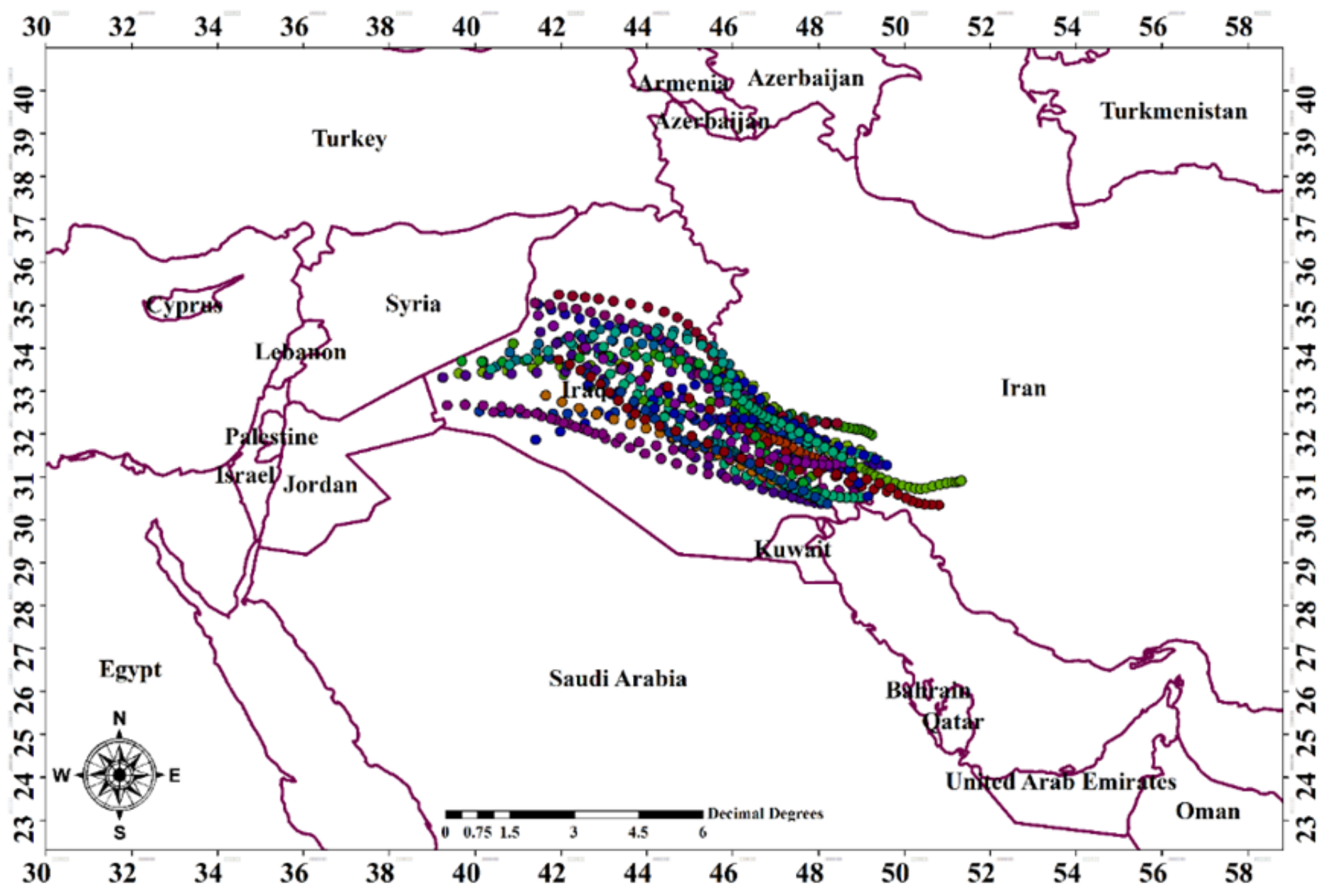

Figure 6

Origin, destination and direction of dust storm source in western Iraq 


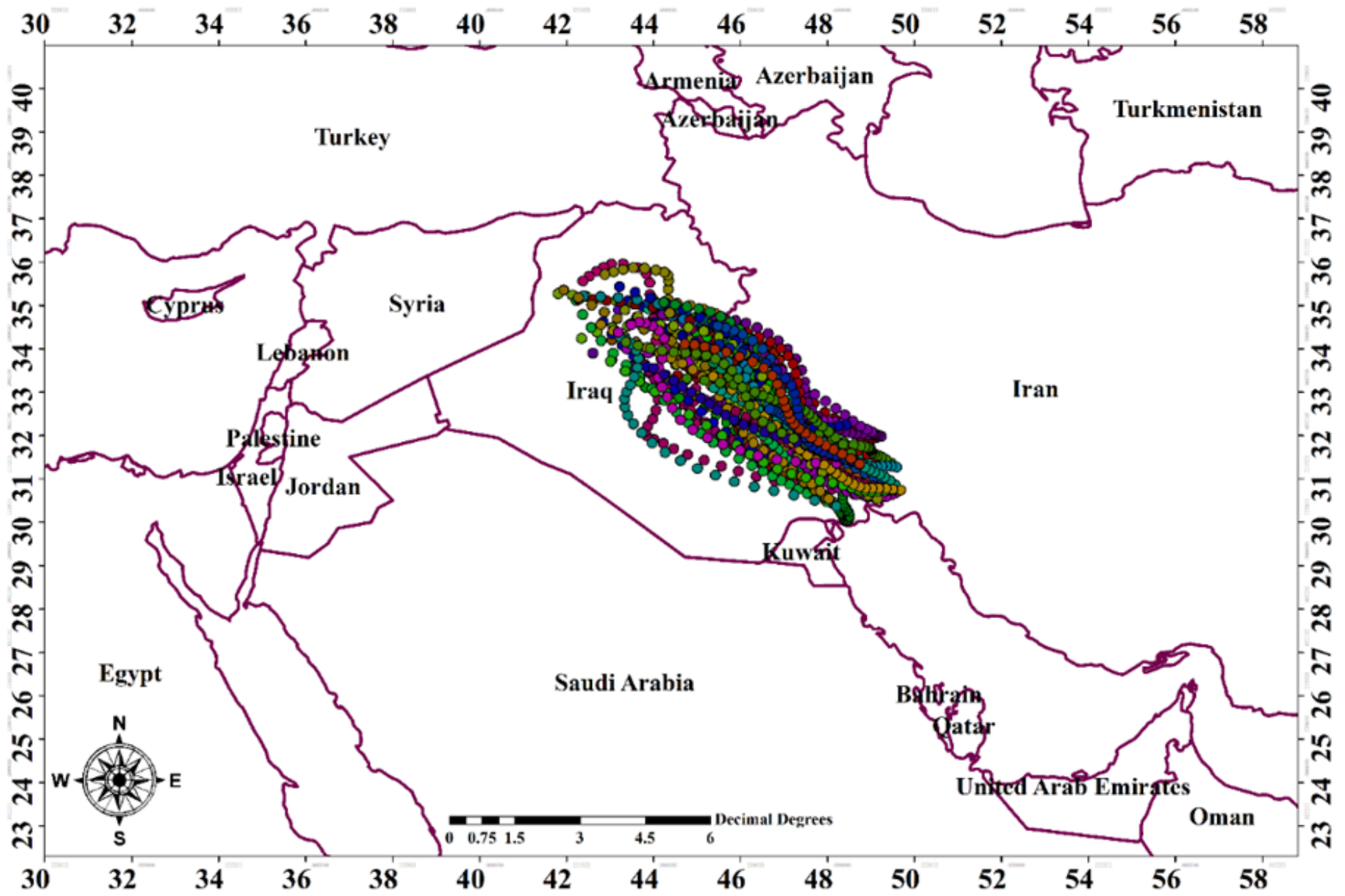

Figure 7

Origin, destination and direction of dust storms in central Iraq 


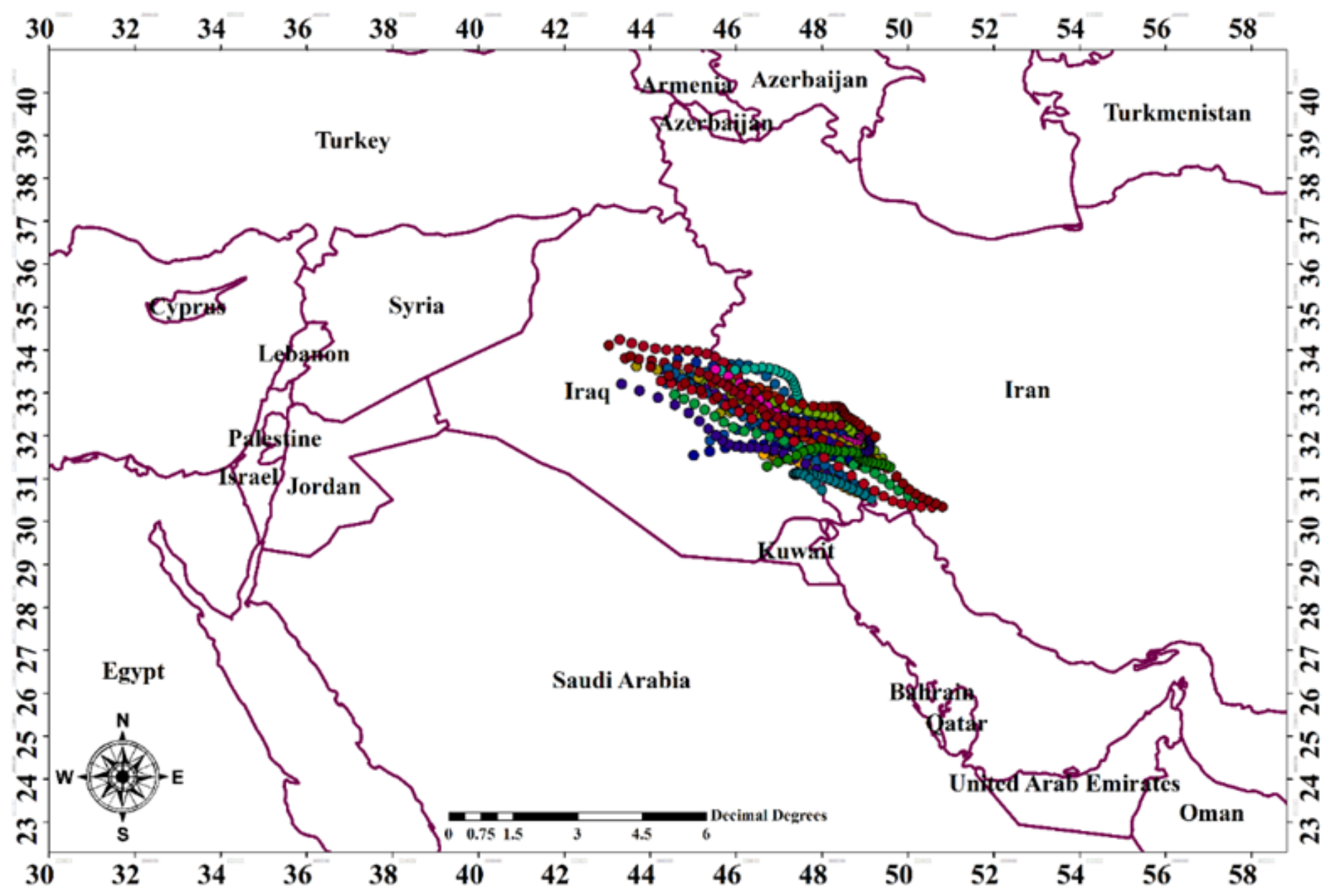

Figure 8

Origin, destination and direction of dust storms in eastern Iraq 


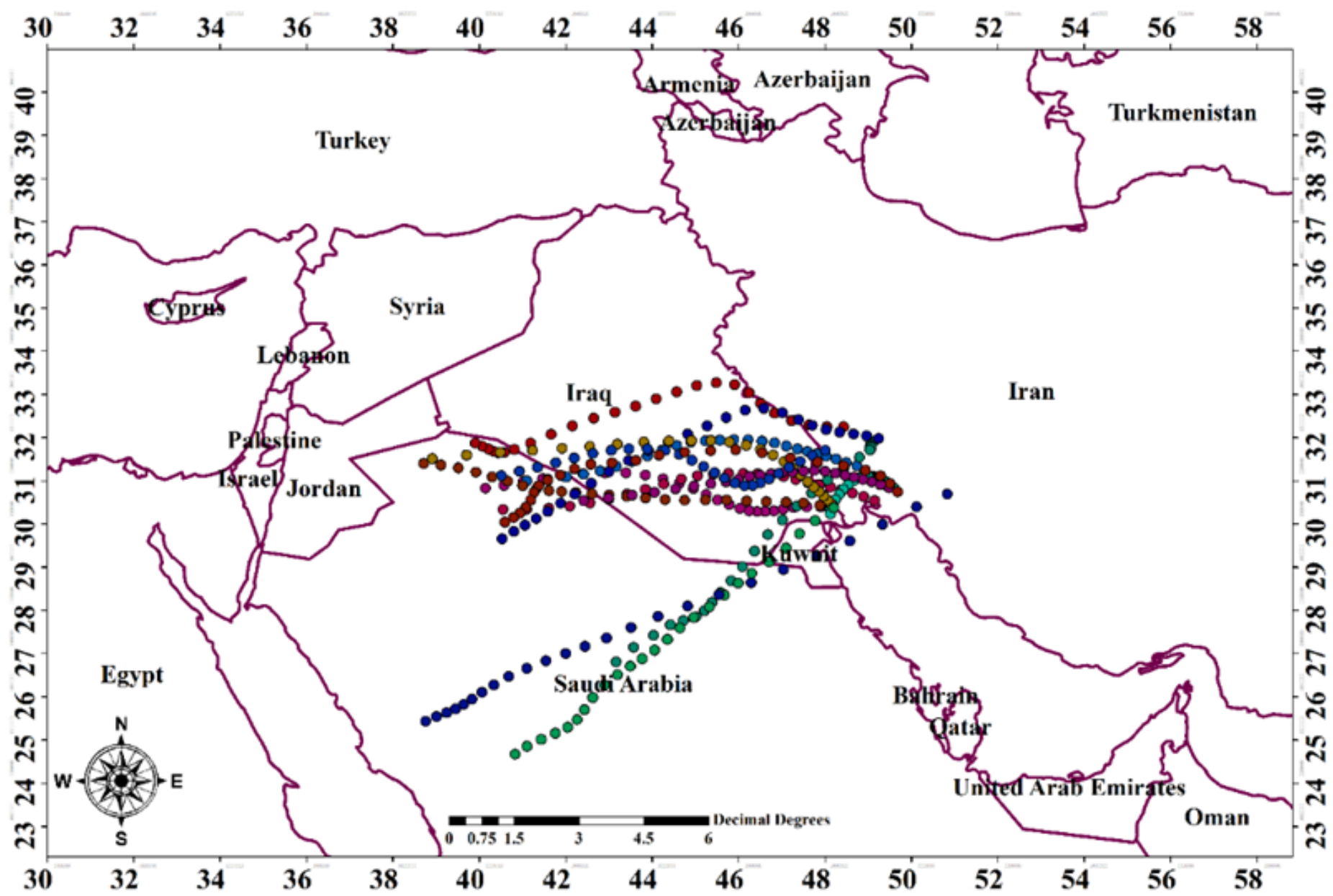

Figure 9

Origin, destination and route of dust storms of Saudi origin 


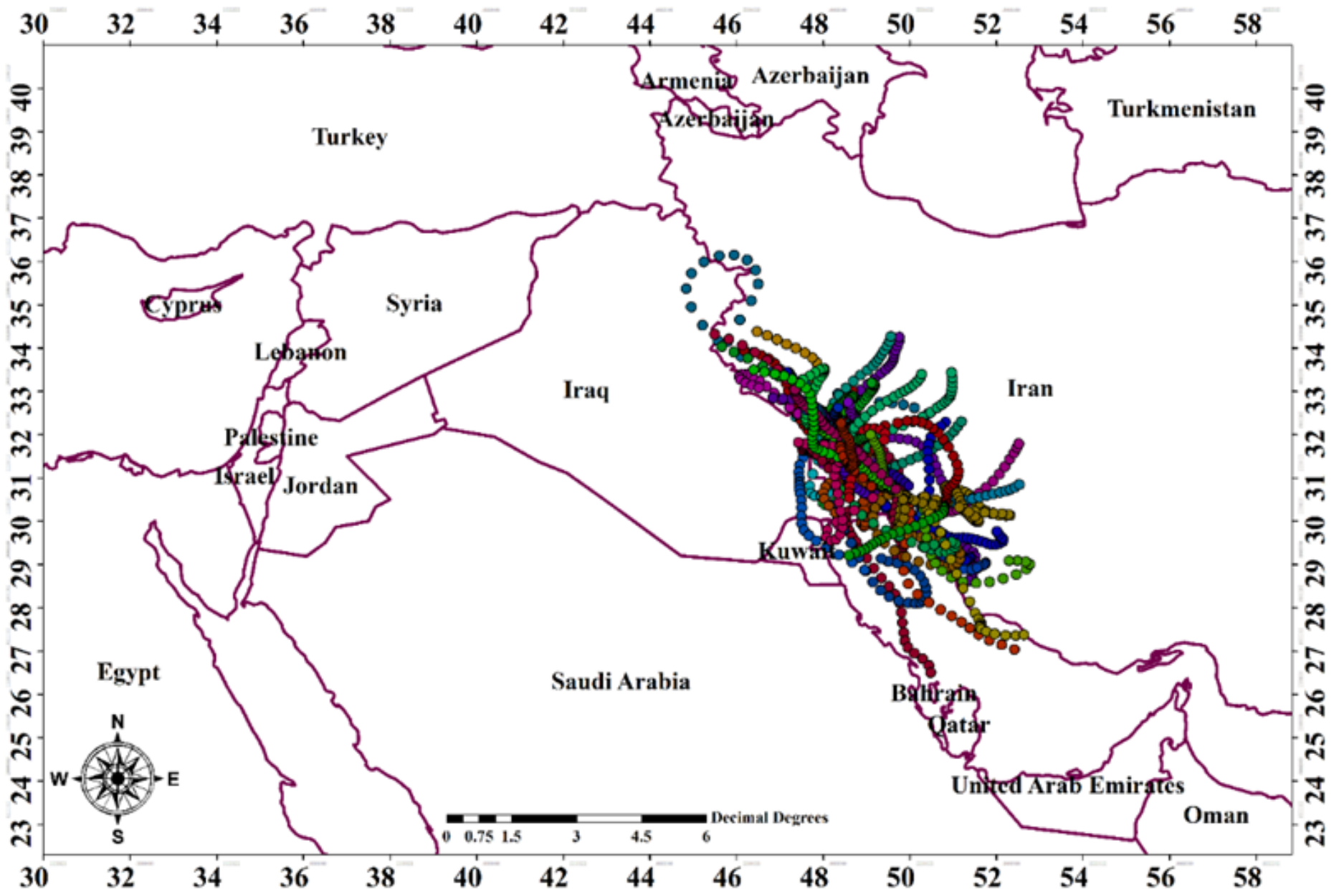

Figure 10

Precipitation status of precipitation months in the study area 


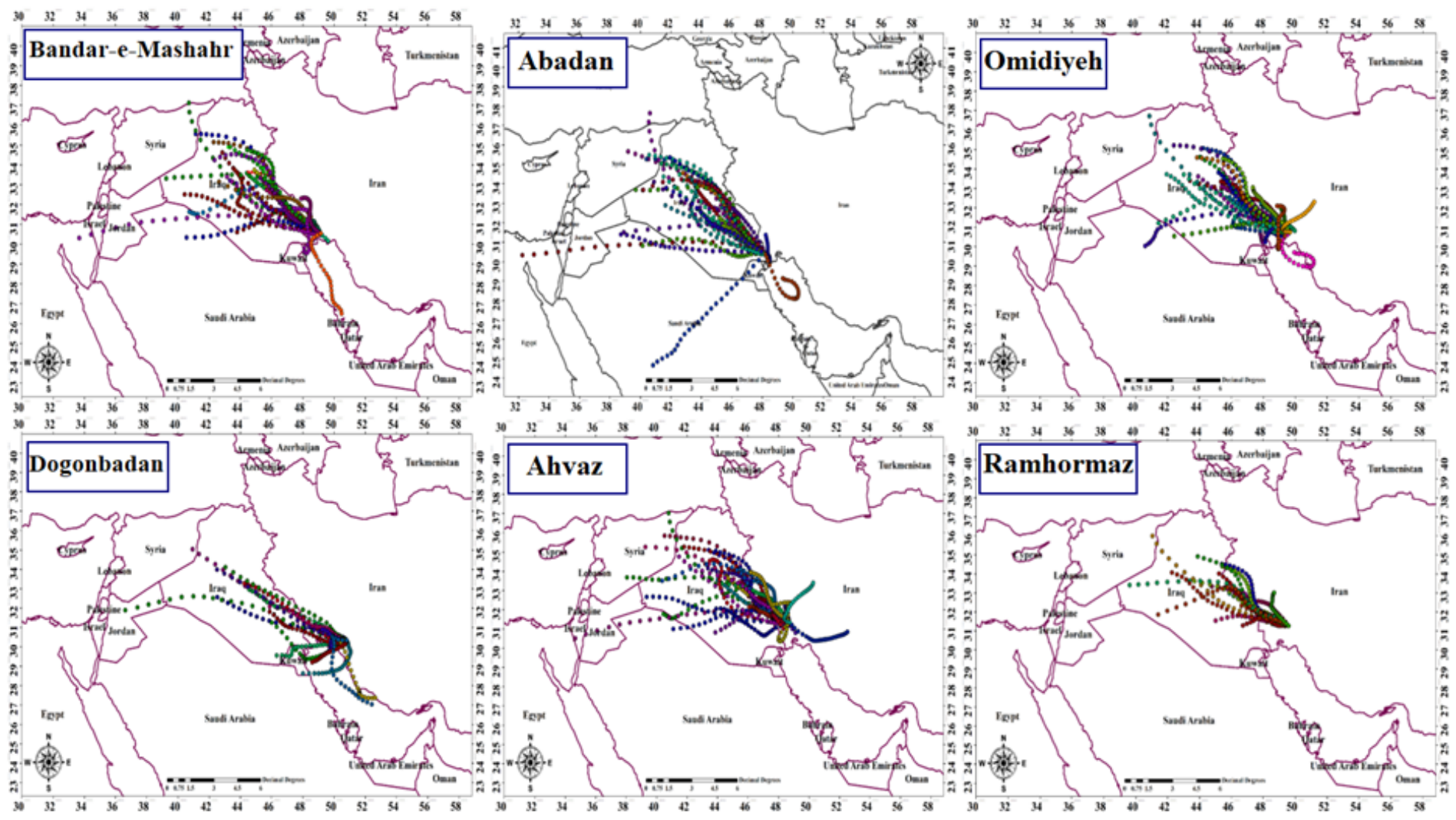

Figure 11

Origin, destination and route of dust storms entering stations (Bandar Mahshahr, Abadan, Omidieh, Dogonbadan, Ahvaz and Ramhormoz). 


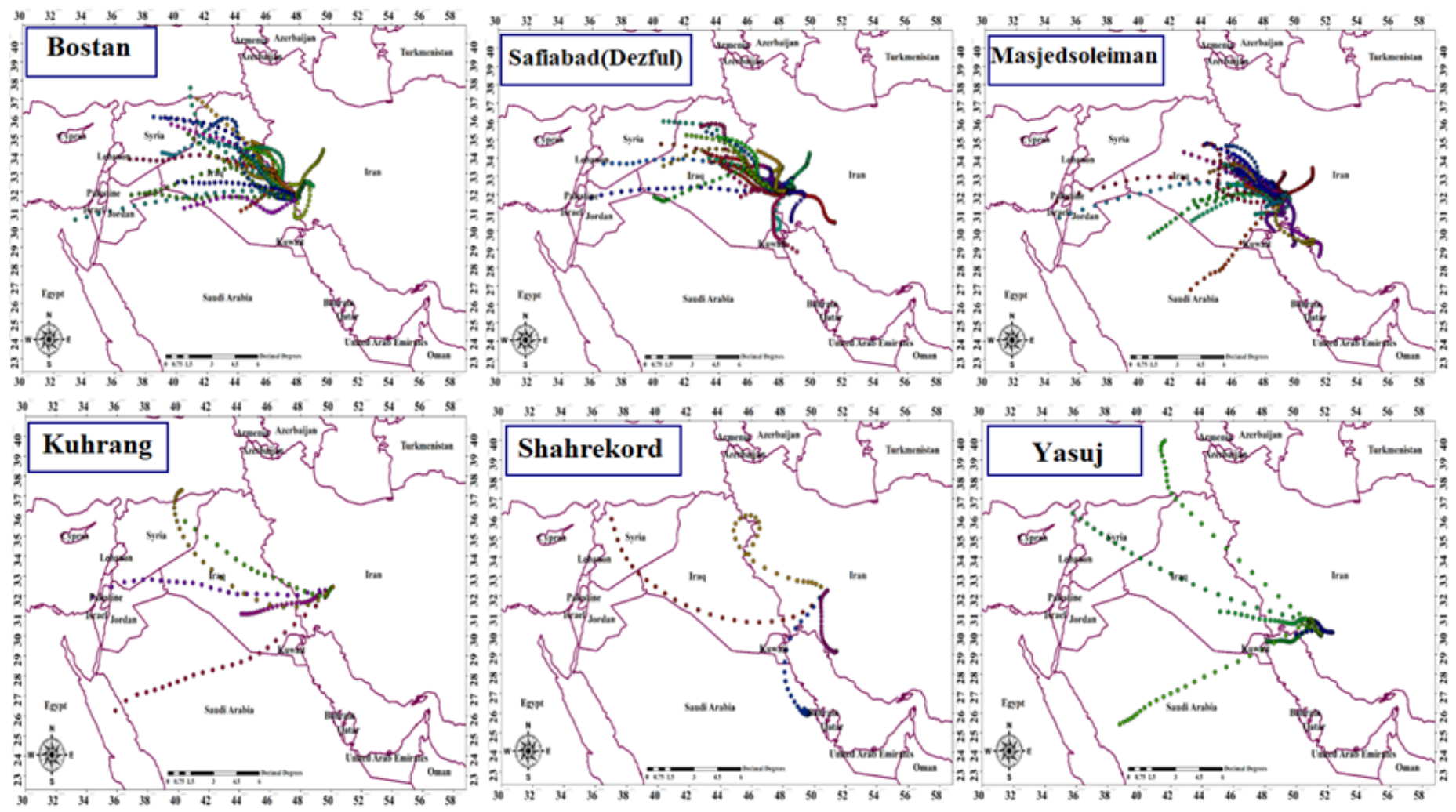

Figure 12

Origin, destination and direction of dust storms entering the stations (Bostan, Safiabad Dezful, Masjed Soleiman, Koohrang, Shahrekord and Yasuj) 